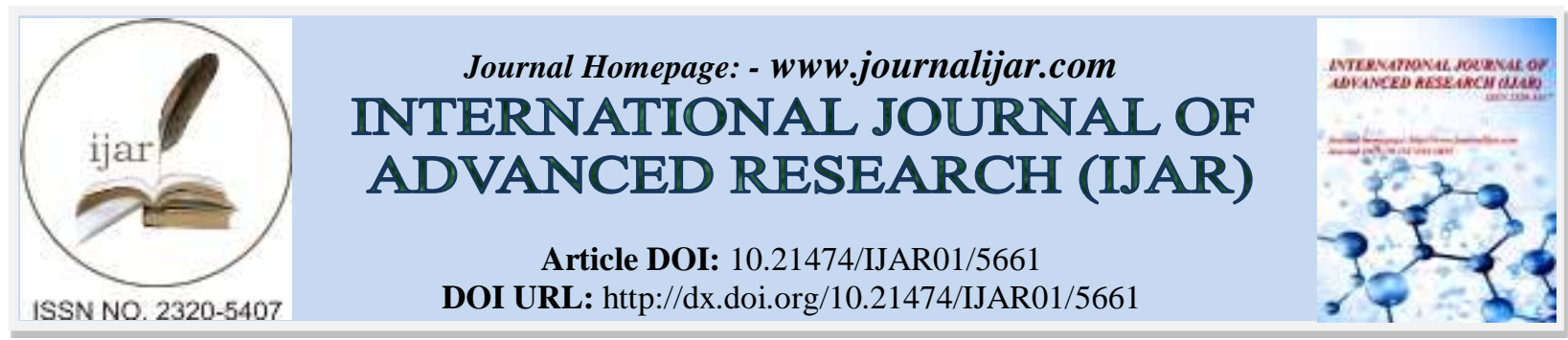

RESEARCH ARTICLE

\title{
STUDY ON BACTERIAL AND MYCOTIC INFECTION OF THE MIDDLE EAR.
}

Fathy Mohamed E. Serry ${ }^{1}$, Ashraf Ahmed Kadry Yosusef ${ }^{1}$ and Fatma Ahmed N. M. H. Elmeselhy ${ }^{2}$. 1. Professor of Microbiology \& Immunology, Faculty of Pharmacy, Zagazig University, Egypt.

2. Pharmacist, Zagazig Fever Hospital, Ministry of Health, Egypt.

\section{Manuscript Info}

Manuscript History

Received: 19 August 2017

Final Accepted: 21 September 2017

Published: October 2017

Key words:-

Otitis media (OM), chronic suppurative otitis media (CSOM), Pseudomonas aeruginosa \& antibiotic resistance.

\section{Abstract}

Otitis media $(\mathrm{OM})$ is an inflammatory disease of the mucosal lining of the middle ear and is most commonly caused by the build-up of fluid behind the ear drum, as a result of a blockage to the Eustachian tube. It is more common in the developing nations with prevalence up to $11 \%$. The aetiology and pathogenesis of OM are multifactorial and include genetic, infections, allergy, environmental and racial factors. The Aims of the work were identification of bacteria and fungi that cause OM, determination of susceptibility of isolates to different antimicrobial agents $\&$ investigation of the possible mechanisms of antimicrobial resistance.

Patients \& methods: This study was carried out in the Microbiology and Immunology Department, Faculty of Pharmacy, Zagazig University in collaboration with Ear, Nose \& Throat (ENT) Department, Zagazig University Hospitals during the period from February 2013 to February 2016. 85 patients with otitis media who were attending the out-patient clinic of ENT Department were included in the study.

Results: There were 37 males and 48 females. Their ages ranged from 1.5 to 60 years. In our study Pseudomonas aeruginosa, Staphylococcus aureus, Streptococcus pneumoniae, Proteus mirabilis, Aspergillus niger and Aspergillus fumigatus were the most important organisms associated with middle ear infection. For Gram negative bacteria, imipenem, amoxicillin-clavulanic acid, cefotaxime, levofloxacin and amikacin appear to be the first line antibiotics to treat chronic suppurative otitis media. For Gram positive bacteria, imipenem, vancomycin, sulfamethoxazole/trimethoprim, levofloxacin, ciprofloxacin and clindamycin appear to be the first line antibiotics in the treatment.

Conclusion: Bacteriological and mycological tests should be carried out before starting treatment of otitis media. The antibiotic susceptibility patterns must be continuously and periodically evaluated to decrease the risk of resistant strains.

Copy Right, IJAR, 2017,. All rights reserved. 


\section{Introduction:-}

Otitis media is an inflammation of the middle ear mucosa which also may involves the mastoid air cells. By the end of their first year, $86 \%$ of children will experience at least 1 episode of acute otitis media (AOM) (BardleyStevenson et al., 2008).

Global reports show that Haemophilus influenzae and Streptococcus pneumoniae are the most prevalent organisms responsible for AOM (Sierra et al., 2011).

Chronic otitis media (COM) is a permanent abnormality on the tympanic membrane following a long standing middle ear infection emanating from previous AOM or negative pressure to the middle ear. Chronic suppurative otitis media (CSOM) is the most severe form of $\mathrm{OM}$ and represents the most important cause of moderate conductive hearing loss in many developing countries (Chirwa et al., 2015).

A number of factors may contribute to the development of ear infections. Most experts consider Eustachian tube dysfunction to be the primary cause for both acute and chronic ear infections. Obstruction at the Eustachian tube isthmus (i.e., the narrowest portion) results in accumulation of middle ear secretions; secondary bacterial or viral infection of the effusion causes suppuration and features of AOM (Rovers et al., 2004).

\section{The Aims of the work:-}

This study aimed at identification of bacteria and fungi that cause otitis media, determination of susceptibility of isolates to antimicrobial agents \& investigation of the possible mechanisms of antimicrobial resistance.

\section{Materials And Methods:-}

This study was carried out in the Microbiology and Immunology Department, Faculty of Pharmacy, Zagazig University on 85 patients suffering from ear discharge secondary to otitis media who were attending the out-patient clinic of ENT Department, Zagazig University Hospitals during the period from February 2013 to February 2016. All patients included in this study were not using local and/or systemic antibiotics for one week before obtaining the samples.

Ear swabs specimens were obtained, after cleaning the external auditory canal of cerumen with sterile saline and $70 \%$ alcohol swab. Specimens were handled according to the approved microbiological procedures as described by Koneman et al (1997), transported to laboratory, examined and cultured within one hour of collection.

Ear swabs were streaked directly on a) nonselective media; Nutrient agar and Blood agar, and b) selective media; Chocolate agar, MacConkey agar, Cetrimide agar, Mannitol salt agar and Sabouraud's dextrose agar (SDA) with chloramphenicol and gentamicin then incubated at $37^{\circ} \mathrm{C}$ for 24 hours except of SDA plates were incubated at $30^{\circ} \mathrm{C}$ and the cultures paraffin sealed plates were held for 4 weeks and were examined twice weekly for growth. The isolated bacterial colonies and Candida were microscopically examined after Gram staining (Collee et al., 1996). Mould cultures were mounted into lactophenol cotton blue stain and examined microscopically (Davise, 2011). Slide culture was prepared according to Riddel, (1950) for mould identification. Candida isolated colonies were presumptively identified according to their characters on SDA (Rippon, 1982). Aspergillus species were cultured on Sabouraud's dextrose agar (SDA), Malt extract agar and Czapek Dox Agar. The plates were sealed by paraffin film and held for 4 weeks examined twice weekly for growth. Morphological examination of species was made with naked eye (Johnston and Booth, 1983; Raper and Fennell, 1965). Further identification for isolated bacteria was done by specific biochemical reactions.

Different bacterial isolates were tested for their susceptibility to different antimicrobial agents by the Kirby- Bauer's disc diffusion method according to CLSI (2012) criteria. The MIC of the antibiotics carried out by broth microdilution method and interpreted according to CLSI (2012) guidelines.

The antifungal susceptibility tests were carried out by Etest method according to Richard et al (2007).

According to CLSI (2012), determination of methicilline resistance Staphylococcus aureus (MRSA), test for inducible clindamycin resistance (D-test) and phenotypic detection of $\beta$-lactamases were performed. 
Effect of efflux pump inhibitor carbonyl cyanide 3-chlorophenyl hydrazone (CCCP) on susceptibility of Pseudomonas aeruginosa isolates to antimicrobial agents piperacillin, gentamicin, amikacin, ciprofloxacin, levofloxacin, aztreonam and cefepime was tested out according to Abdi-Ali et al (2007).

Efflux mechanism in Pseudomonas aeruginosa isolates was screened by accumulation of ethidium bromide, in presence and absence of efflux inhibitor, using a modification of the methods of Kaatz et al (2003), and Nishino and Yamaguchi (2004).

Molecular identification of Staphylococcus aureus isolates, a. isolating Genomic DNA from MRSA performed according to Promega kit manufacture's instruction, b. PCR Assay for detection of mec-A and erm-A genes (Birgit et al., 2003), Electrophoresis and visualization of PCR amplicons was performed according to Lee and Costumbrado (2012).

\section{Results:-}

During this study, a total of 120 isolates were obtained from 85patients. Single isolate (58.82\%) were obtained from 50 specimens and double organisms $(41.18 \%)$ were obtained from 35 specimens. samples were either mixed bacterial combination $27(80 \%)$ or combination of bacteria and fungi $6(20 \%)$.

The 94 bacterial isolates were classified to 37 (30.83\%) Gram positive and 57 (47.5\%) Gram negative and the 26 fungal isolates comprising 24 (20\%) mould and $2(1.67 \%)$ yeast (figure 1).

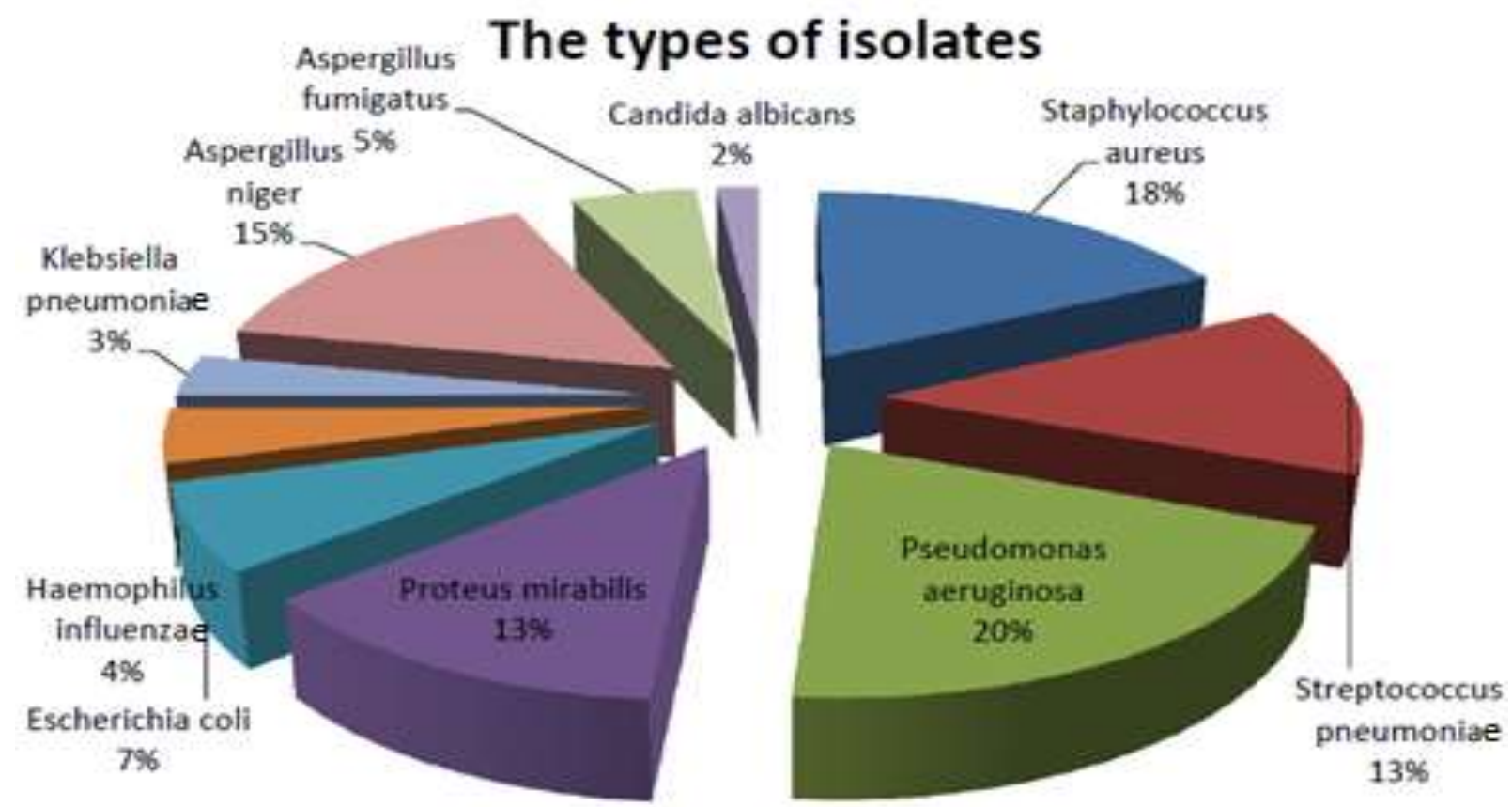

Figure (1):- The distributions of types and percentages of isolates

The bacterial isolates were tested for their susceptibility to the different antimicrobial chemotherapeutic agents by disk diffusion method; the diameters of inhibition zones were measured and interpreted according to CLSI (2012) guidelines (table 1).

Table (1):- the susceptibility of bacterial isolates to the different antimicrobial chemotherapeutic agents 


\begin{tabular}{|c|c|c|c|c|c|c|c|c|c|c|c|c|c|c|c|c|c|c|c|c|c|c|}
\hline Microorganisms & 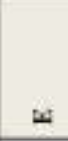 & $\bar{\Sigma}$ & $\lesssim$ & $\frac{5}{2}$ & 년 & $\bar{a}$ & इ & 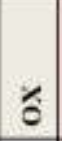 & $\frac{0}{2}$ & 0 & $\hat{\overline{0}}$ & z & $\frac{1}{2}$ & $\leq$ & $\stackrel{\simeq}{\vec{u}}$ & \pm & 5 & 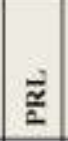 & 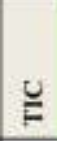 & है & ثี & $\sum$ \\
\hline S. aureus & 12 & 13 & 17 & 17 & 4 & 21 & 0 & 2 & 16 & 16 & 16 & 7 & 11 & 21 & - & - & - & - & - & - & $=$ & - \\
\hline Strep.pncumoniac & 14 & - & 14 & 14 & - & 16 & - & 11 & 16 & 13 & 16 & - & - & 16 & 16 & 16 & 16 & $=$ & - & - & $=$ & - \\
\hline$P$ aenginosa & - & - & - & 2 & 4 & 24 & - & - & 20 & 6 & 5 & 2 & 3 & - & - & 16 & 8 & 1 & 12 & 25 & 21 & 21 \\
\hline P. mirabilis & - & - & - & 10 & 4 & 13 & - & - & 14 & 9 & 10 & 11 & 13 & - & - & - & 15 & 11 & - & - & 15 & - \\
\hline E coli & - & - & - & 4 & 2 & 8 & - & - & 6 & 8 & 5 & 5 & 7 & - & - & - & 8 & 4 & - & - & 8 & - \\
\hline K. paeumoniac & - & - & - & 0 & 1 & 4 & - & - & 4 & 4 & 3 & 1 & 2 & - & - & 4 & 3 & 2 & - & - & 4 & - \\
\hline H. influesza & - & 5 & - & 4 & - & 5 & 1 & & 5 & 4 & 5 & $=$ & $=$ & $=$ & $=$ & 5 & 5 & - & $=$ & - & - & 5 \\
\hline $\begin{array}{l}\text { No of tested } \\
\text { bacteria }\end{array}$ & 46 & 26 & 47 & 94 & 73 & 94 & 26 & 46 & 94 & 94 & 94 & 73 & 73 & 47 & 16 & 50 & 73 & 52 & 25 & 25 & 52 & 30 \\
\hline Total & 25 & 18 & 31 & 51 & 15 & 91 & 1 & 13 & 81 & 60 & 60 & 26 & 36 & 47 & 16 & 41 & 55 & 18 & 12 & 25 & 48 & 26 \\
\hline$\%$ of effectiveness & 54.3 & 79 & 66 & 84.3 & 20.5 & 968 & 3.8 & 28.3 & 86.2 & 63.8 & 63.8 & 35.6 & 49.3 & 100 & 100 & 82 & 753 & 34.6 & 48 & 100 & 92.3 & 86.6 \\
\hline
\end{tabular}

Fungal isolates were tested for their susceptibility to Itraconazole and Amphotericin B by Etest method. The filamentous fungi (Aspergillus fumigatus and Aspergillus niger) Etest results were interpreted according to CLSI (M38-A) while yeast was interpreted according to CLSI (M27-A3) (table 2).

Table (2):- Etest ranges and results interpretation for fungal isolates to itraconazole and amphotericin B.

\begin{tabular}{|c|c|c|c|c|c|c|c|c|c|c|}
\hline \multirow[t]{3}{*}{ Microorganisms } & \multicolumn{5}{|c|}{ Itraconazole result interpretation } & \multicolumn{5}{|c|}{ Amphotericin B result interpretation } \\
\hline & \multirow[t]{2}{*}{ MIC range } & \multicolumn{2}{|c|}{ Sensitive } & \multicolumn{2}{|c|}{ Resistance } & \multirow[t]{2}{*}{ MIC range } & \multicolumn{2}{|c|}{ Sensitive } & \multicolumn{2}{|c|}{ Resistance } \\
\hline & & No. & $\%$ & No. & $\%$ & & No. & $\%$ & No. & $\%$ \\
\hline Aspergillus niger & $0.064-0.25$ & 18 & 100 & $\mathbf{0}$ & $\mathbf{0}$ & $0.064-0.5$ & 18 & 100 & $\mathbf{0}$ & $\mathbf{0}$ \\
\hline Aspergillus fumigatus & $0.023-0.125$ & 6 & 100 & $\mathbf{0}$ & $\mathbf{0}$ & $0.047-0.25$ & 6 & 100 & $\mathbf{0}$ & $\mathbf{0}$ \\
\hline Candida albicans & $0.19-0.25$ & 2 & 100 & $\mathbf{0}$ & $\mathbf{0}$ & $0.12-0.25$ & 2 & 100 & $\mathbf{0}$ & $\mathbf{0}$ \\
\hline
\end{tabular}

Test for inducible clindamycin resistance showed that, two Staphylococcus aureus isolates resisted to erythromycin and had intermediate resistance to clindamycin were found to be positive inducible clindamycin resistance test (figure 2). 


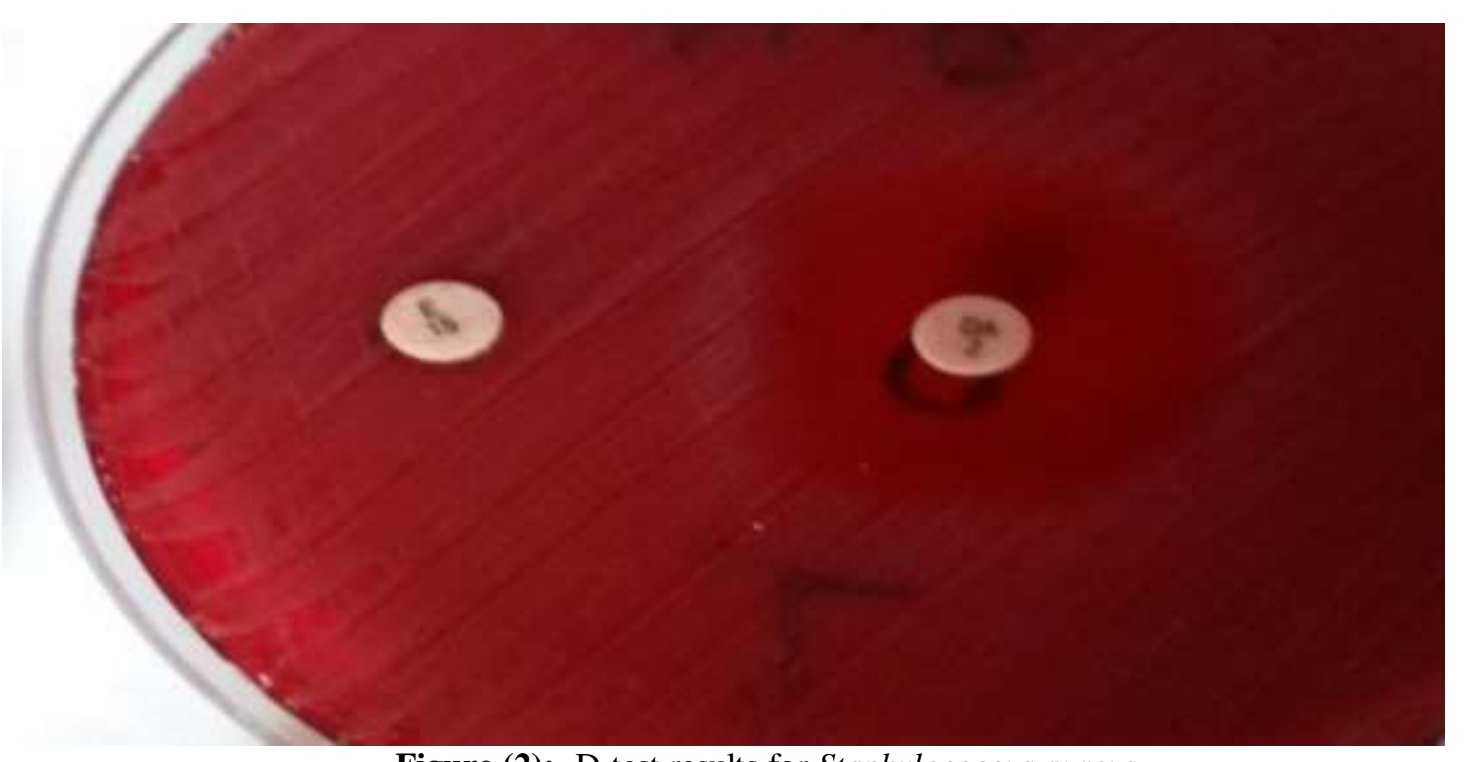

Figure (2):- D-test results for Staphylococcus aureus

Phenotypic detection of $\beta$-lactamases done for Klebsiella pneumoniae isolate and Haemophilus influenzae isolates. These phenotypic confirmatory tests showed one positive Klebsiella pneumoniae isolate that was EBLs producter and showed four Haemophilus influenzae isolates that were $\beta$ - lactamase producer (carried out by using Cefinase disks).

Effect of efflux pump inhibitor carbonyl cyanide 3-chlorophenyl hydrazone (CCCP) on susceptibility of Pseudomonas aeruginosa isolates to antimicrobial agents piperacillin, gentamicin, amikacin, ciprofloxacin, levofloxacin, aztreonam and cefepime revealed that resistance of Pseudomonas aeruginosa isolates to these antimicrobial agents may be due to efflux activity.

The function of efflux pump were tested in 22 piperacillin resistant Pseudomonas aeruginosa isolates by observation of accumulation of ethidium bromide, in presence and absence of efflux inhibitor dinitrophenol. Increased fluorescence was observed in cells treated with DNP compared with control cells demonstrated the activity of efflux pump in extrusion of ethidium bromide. The toluene permealized cells was used as positive control for accumulation of ethidium bromide. All tested Pseudomonas aeruginosa isolates demonstrated positive efflux pump activity (Figure 3).

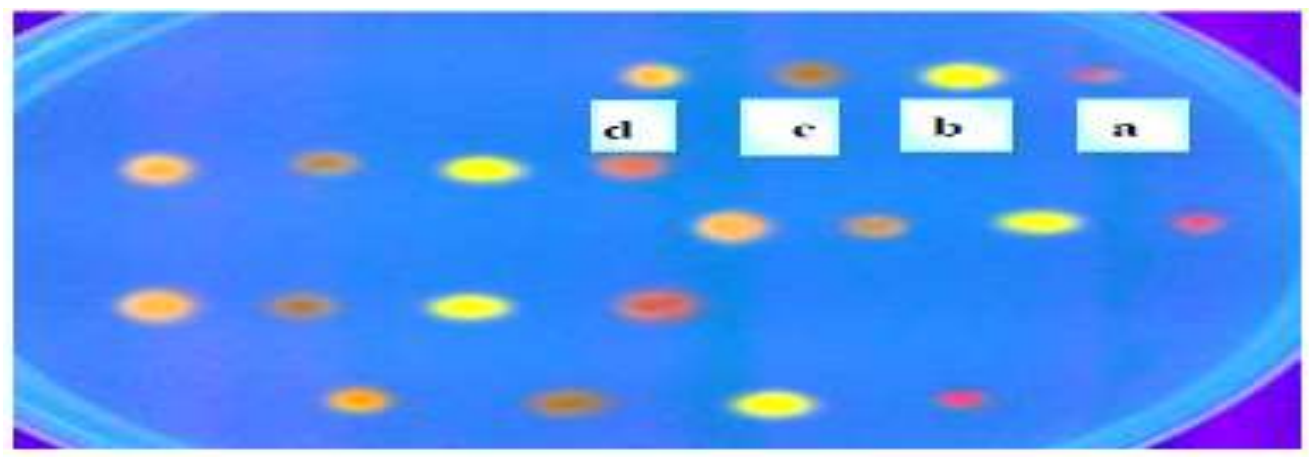

Figure (3):- Ethidium bromide accumulation in Pseudomonas aeruginosa cells after varies treatments; spot (a), cells treated with glucose; spot (b), cells treated with dinitrophenol; spot (c), cells without any treatment; and spot (d), cells treated with toluene.

Thirteen Staphylococcus aureus isolates (72.2\%) were confirmed as MRSA by amplification of fragment of mec-A genes, each of them had band at $532 \mathrm{bp}$ indicating for the presence of mec- $A$ gene (figure 4). While 5 
Staphylococcus aureus isolates (27.8\%) were confirmed as MSSR as they had no bands indicating for the presence of mec- $A$ gene.

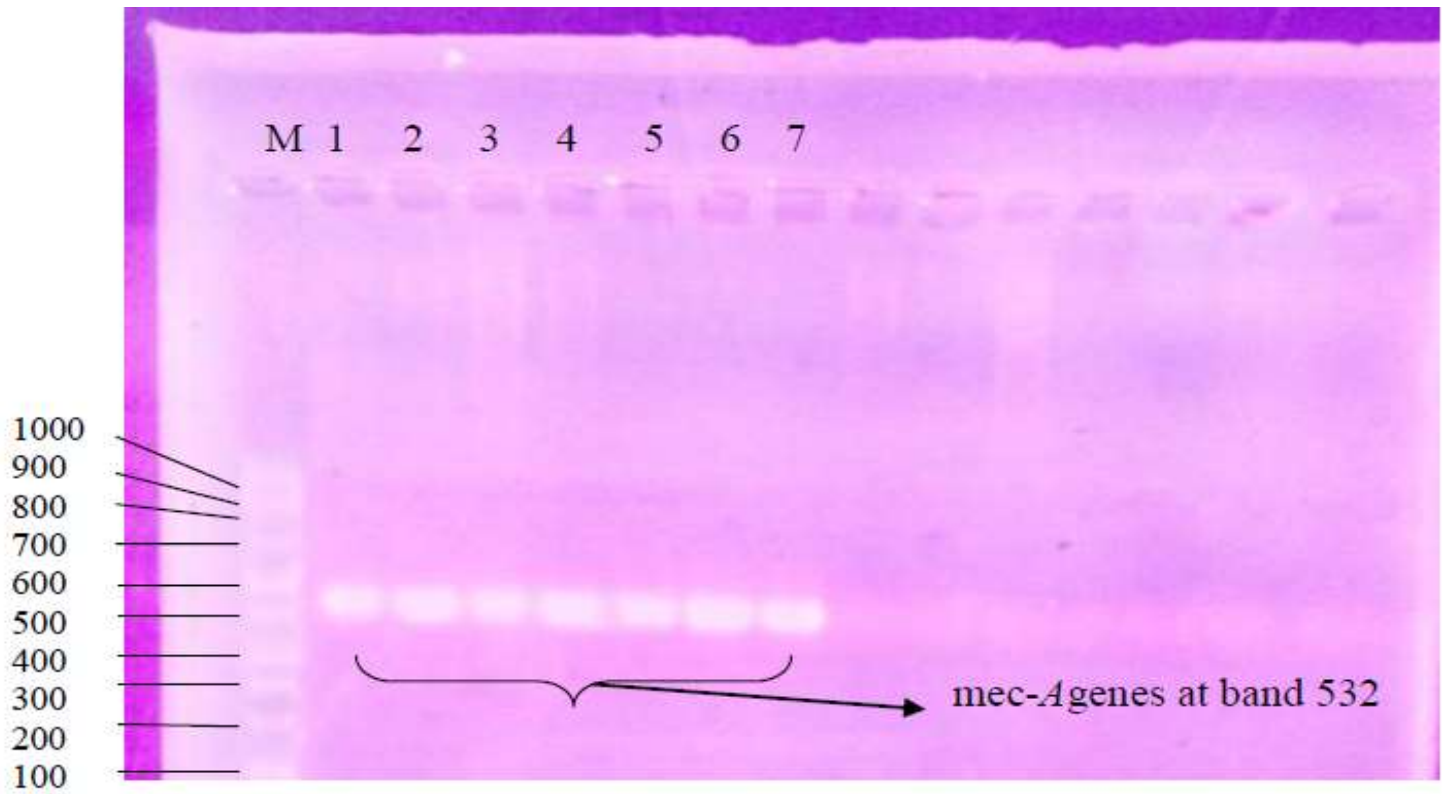

Figure (4):- Electrophoretogram of erm-A gene Staphylococcus aureus isolates

Only one Staphylococcus aureus isolate (12.5\%) that had band at $190 \mathrm{bp}$ indicating for the presence of erm-A gene (figure 5).

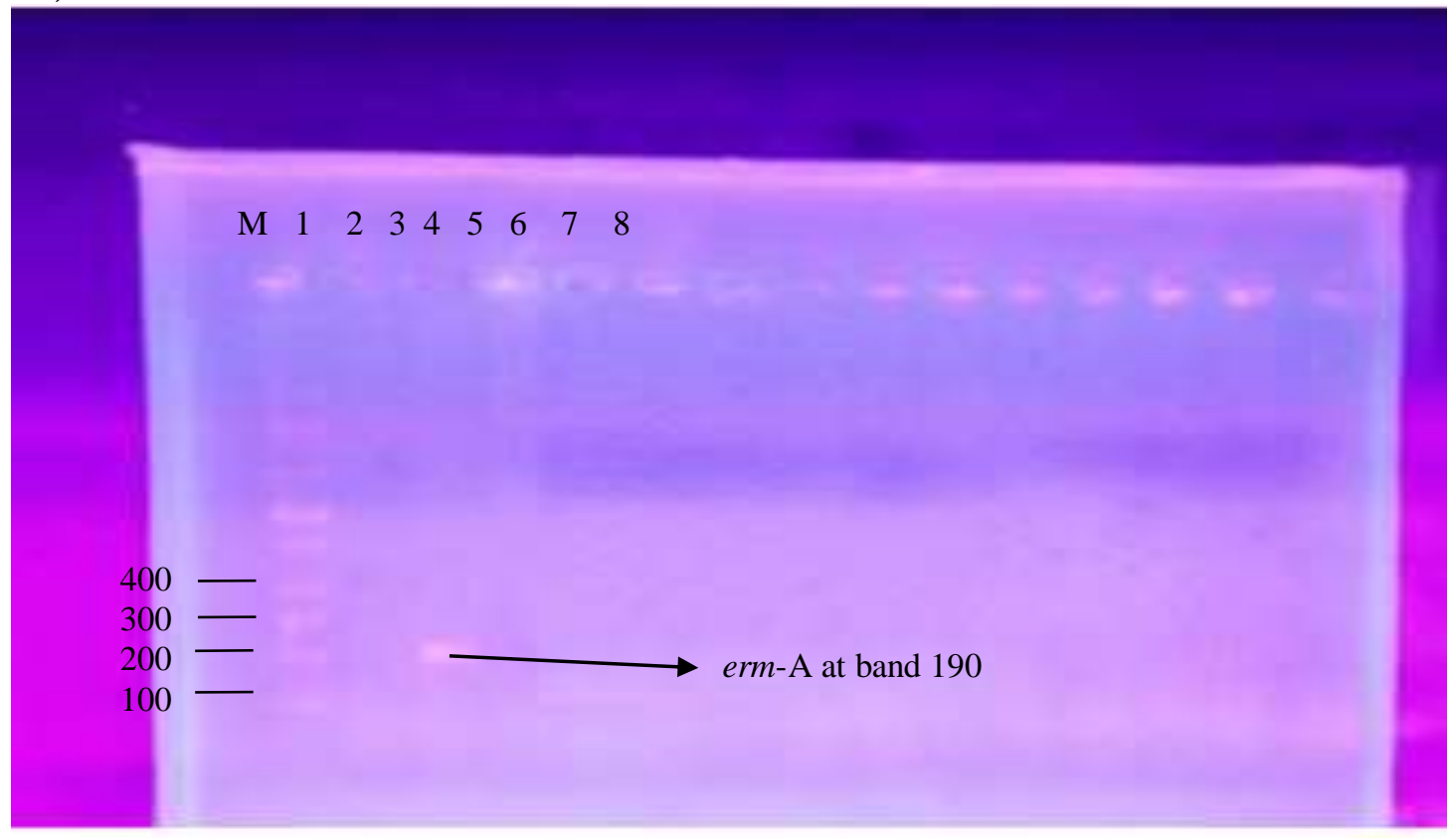

Figure (5):- Electrophoretogram of erm-A gene Staphylococcus aureus isolates.

\section{Discussion:-}

$\mathrm{OM}$ is a serious healthcare concern worldwide, not only because of the distress it causes to the patient and their family but also because of the substantial economic burden it imposes on the health care system (Ologe and Nwawolo, 2002). 
In our study, Analysis of the total 85 samples obtained from 85 patients (there diagnoses vary from AOM, COM to CSOM) revealed that mono-microbial growth was obtained in 50 (58.82\%) of total samples and 35 (41.18\%) of samples yielded poly-microbial growth, this finding agrees with the study of Rajat et al (2013) but disagree with study of Aslam et al (2004). Difference in results could be due to different patient population \& geographical variations.

In the present study, the 94 bacterial isolates (78.33\% of total isolates), comprised 25 (26.6\%) Pseudomonas aeruginosa, 21 (22.3\%) Staphylococcus aureus, 16 (17\%) Streptococcus pneumoniae, 15 (16\%) Proteus mirabilis, 8 (8.5\%) Escherichia coli, 5 (5.4\%) Haemophilus influenzae and 4 (4.2\%) Klebsiella pneumoniae. These findings agree with that of Oni et al (2001). However different rates and order of isolated organisms were reported by Okesola and Fasinam (2012).

In the present study, the most common causative organisms were Gram negative bacteria (47.5\%) then Gram positive bacteria (30.83\%). This agrees with the study of Van Hasselt (2013).

In present study, the most frequently occurring organisms were Pseudomonas aeruginosa (20.3\%) and Staphylococcus aureus (17.5\%). This agrees with results of other authors reporting that, Pseudomonas aeruginosa and Staphylococcus aureus were the most commonly isolated bacteria (Mohammad et al., 2016; Chirwa et al., 2015). Against the present study, Nyembue et al (2003) reported that Proteus mirabilis and enterococci were the most frequently isolated microbes from OM.

In our study, Proteus mirabilis isolates represented $16 \%$ of total bacterial isolates and $12.5 \%$ of total isolates. Maiangwa et al (2016) agrees with our finding, but on the contrary Rejitha et al (2015) reported Proteus mirabilis in 2 isolates that represent $3.77 \%$ of total isolates.

In the present study, Streptococcus pneumoniae represented the second most frequently isolated Gram positive organism (13.3\%). The study done by Abdelraouf et al (2014) disagrees with our study.

In the present study, Haemophilus influenzae isolates represented low incidence (4.2\%) of total isolates. Different result reported by Nwankwo and okeke (2014).

In our study, Escherichia coli and Klebsiella pneumoniae represented $6.7 \%$ and $3.3 \%$ of total isolates, respectively. Our results were comparable to that of Chirwa et al (2015). In Singh et al study (2012), E. coli represented $4 \%$ of total infectious bacteria causes CSOM. Nwankwo and Okeke (2014) obtained a relatively higher rate of $E$. coli $(10.2 \%)$ from otitis media samples.

In the present study, fungal isolates represented $21.67 \%$ of the total isolates. This agrees with the results of Abd alzaher (2004) Different results were found in the study of Susmita et al (2014) who reported Candida albicans as the most common fungal isolates.

In the present study, antibiotic susceptibility tests revealed that all Staphylococcus aureus isolates (100\%) were susceptible to vancomycin. Our finding agrees with Abdelshafy (2015), showed that quinolones were the most effective antibiotic against Staphylococcus aureus.

In the present study, all Pseudomonas aeruginosa isolates (100\%) sensitive to ceftazidime and 96\% were sensitive to imipenem. The results agree with that of Ogbogu et al (2013). Pseudomonas aeruginosa showed also high sensitivity to cefepime (84\%), followed by levofloxacin (64\%). Cefotaxime was less active against most $P$. aeruginosa isolates with resistance rate of $56 \%$. This was in agreement with the study of Harvinder and Seth (2011).

In our study, Fungal isolates Candida albicans, Aspergillus niger and Aspergillus fumigatus were all fully susceptible to the two antifungal agents used amphotericin B and itraconazole (100\% susceptibility rate). This was in agreement with the results Abd al-zaher (2004) stated that Aspergillus niger and Aspergillus fumigatus isolates had acceptably low MICs for amphotericin B and Itraconazole and Candida albicans isolates were fully susceptible to Itraconazole. 
In the current study, $100 \%$ of Staphylococcus aureus isolates that were resistant to erythromycin and intermediated to clindamycin had inducible clindamycin resistance (positive D-test). Yusuf et al (2014) found that out $72.8 \%$ of Staphylococcus aureus isolated that were resistant to erythromycin and susceptible to clindamycin, were positive to D-test.

In the present study, 3.7\% of Enterobacteriaceae isolates (Escherichia coli, Proteus mirabilis and Klebsiella pneumoniae) were found to produce extended spectrum $\beta$-lactamases (ESBLs) that found in $25 \%$ of Klebsiella pneumoniae isolates. These results are different from that of Yusuf et al (2014).

In this study, Reduction in MICs (at least 2 fold) in presence of efflux inhibitor CCCP indicates the presence of proton gradient-efflux pump(s) in our Pseudomonas aeruginosa isolates. The highest rate for reduction in MIC was reported to aztreonam ( 2 to 3 fold reductions in MIC). Levofloxacin MICs decreased by 2 fold after addition of CCCP. Piperacillin, gentamicin, amikacin, ciprofloxacin and cefepime showed 2 to 3 fold reduction in MIC in presence of CCCP. These results are in agreement with that of Adabi et al (2015).

In the current study, the piperacillin resistant Pseudomonas aeruginosa isolates were tested for the possible role of efflux in such resistance by testing the activity of efflux pump through demonstrating the effect of efflux inhibitor (DNP) on ethidium bromide accumulation inside cells. All 22 (100\%) piperacillin resistant Pseudomonas aeruginosa isolates expressed positive efflux pump activity. This finding may indicate the role of efflux mechanism in resistance to piperacillin. This agrees the study of Pournaras et al (2005).

In the present study, by PCR amplification, it was possible to demonstrate the presence of mec- $A$ gene in all 18 oxacillin resistant Staphylococcus aureus isolates, these confirming 13 out of 18 oxacillin resistant Staphylococcus aureus isolates rates (72.2\%) as MRSA. The high prevalence of the MRSA in the current study is in accordance with the results obtained by Al-Khulaifi et al (2009), while Birgit et al (2003) found that all oxacillin-resistant strains carried mec- $A$ gene.

In our study, by PCR amplification it was possible to demonstrate the presence of $\operatorname{erm}(\mathrm{A})$ gene in only one out of 4 erythromycin and/or clindamycin resistant Staphylococcus aureus isolates (25\%). In contrast, Birgit et al (2003) found that $15(65.2 \%)$ out of 23 strains resistant to erythromycin and/or clindamycin had the erm(A) gene.

\section{Conclusion:-}

In our study Pseudomonas, Staphylococcus aureus, Streptococcus pneumoniae, Proteus mirabilis and Aspergillus species were the most important organisms associated with middle ear infection. For Gram negative bacteria, imipenem, amoxicillin-clavulanic acid, cefotaxime levofloxacin and amikacin appear to be the first line antibiotics to treat CSOM. However, imipenem, vancomycin, sulfamethoxazole/trimethoprim, levofloxacin, ciprofloxacin and clindamycin appear to be the first line antibiotics in the treatment of Gram positive bacteria.

The antibiotic susceptibility patterns must be continuously and periodically evaluated to decrease the risk of resistant strains.

\section{References:-}

1. Abd al-zaher, E.; Azzazy E.; and Azzab M.; 2004. A study on microorganisms causing CSOM with concentration on fungal infection and risk factors predisposing to it. www.eulc.edu.eg/eulc_v5/Libraries/Thesis/BrowseThess

2. Abdelraouf, E.; Noor, T.; and Salah, N.; 2014. The bacterial etiology of otitis media and their antibiogram among children in Gaza strip. Egypt Journal of Ear Nose Throat Allied Sciences 15: P: 87-91.

3. Abdelshafy, I.; Haleem, A.; and Khalil, Y.; 2015. Microbiology of Chronic Suppurative Otitis Media; study of the role of bacterial biofilm and fungal infection. Journal of Otolaryngol ENT Research 3:00051.

4. Abdi-Ali, A.; Rahmani-Badi, A.; and Falsafi, T.; 2007. Study of antibiotic resistance by efflux in clinical isolates of Pseudomonas aeruginosa. Pakistan Journal of biological science 10: P: 924-927.

5. Adabi, M.; Mahshid, T.; and Leila, A.; 2015. Spread of Efflux Pump Overexpressing-Mediated Fluoroquinolone Resistance and Multidrug Resistance in Pseudomonas aeruginosa by using an Efflux Pump Inhibitor. Infection \& Chemotherapy Journal 47: P: 98-104. 
6. Al-Khulaifi, M.; Amin, N.; and Ali, A.; 2009. Phage typing, PCR amplification for mecA gene and antibiotic resistance patterns as epidemiologic markers in nosocomial outbreaks of methicillin resistant Staphylococcus aureus. Saudi Journal of Biological Sciences 16: P: 37-49.

7. Aslam, M.; Ahmed, Z.; and Azim, R.; 2004. Microbiology and drug sensitivity patterns of chronic suppurative otitis media. Journal of College Physicians Surgery Pakistan 14: P: 459-461.

8. Bardley-Stevenson, C.; O"Neill, P.; and Roberts, T.; 2008: Otitis media in children (acute). BMJ Clinical Evidence 285: P: 416-423.

9. Birgit, S.; Christiane, K.; and Guido, W.; 2003. Multiplex PCR Assay for Simultaneous Detection of Nine Clinically Relevant Antibiotic Resistance Genes in Staphylococcus aureus. Journal of Clinical Microbiology 41: P: 4089-4094.

10. Chirwa, M.; Mulwafu, W.; Aswani, JM.; Masinde, PW.; Mkakosya, R.; and Soko, D.; 2015. Microbiology of chronic suppurative otitis media at Queen Elizabeth central hospital, Blantyre, Malawi: A cross-sectional descriptive study. Malawi Medical Journal 27: P: 120-124.

11. Clinical and Laboratory Standards Institute, 2008. Reference method for broth dilution antifungal susceptibility testing of yeasts; approved standard-third edition; CLSI document M27-A3. Clinical and Laboratory Standards Institute, Wayne.

12. Clinical and Laboratory Standards Institute, 2008. Reference method for broth dilution antifungal susceptibility testing of fi lamentous fungi; approved standard CLSI document M38-A2. Clinical and Laboratory Standards Institute, Wayne.

13. Clinical and Laboratory Standards Institute. 2012. Performance Standards for Antimicrobial Disk Susceptibility Tests; Approved Standard-Eleventh Edition. CLSI document M02-A11 (ISBN 1-56238-781-2 [Print]; ISBN 1-56238-782-0 [Electronic]). Clinical and Laboratory Standards Institute, 950 West Valley Road, Suite 2500, Wayne, Pennsylvania 19087 USA.

14. Collee, J.; Miles, R.; and Watt, B.; 1996. Tests for the Identification of Bacteria: In practical medical microbiology (14 ${ }^{\text {th }}$ Ed.), P: 2312-2422. Churchill Livingstone: London.

15. Davise, H.L.; 2011. Medically important Fungi: A guide to identification; $\left(5^{\text {th }}\right.$ Ed.) P: 14-25. Washington: American society for microbiology.

16. Harvinder, K.; and Seth, S.; 2011. Bacterial and Fungal Study of 100 Cases of Chronic Suppurative Otitis Media. Journal of Clinical and Diagnostic Research 5: P: 1224-1227.

17. Johnston A.; and Booth, C.; (1983). Plant pathologist's pocketbook. (2 ${ }^{\text {nd }}$ Ed.), P: 324-378. Common wealth Mycological Institute, UK.

18. Kaatz, W.; Moudgal, V.; and Seo, M.; 2003. Phenothiazines and thioxanthenes inhibit multidrug efflux pump activity in Staphylococcus aureus. Antimicrobial Agents Chemotherapy Journal 47: P: 719-726.

19. Koneman, E.; Allen, S.; and Janda, W.; 1997. Koneman's Colour Atlas and Textbook of diagnostic microbiology ( $5^{\text {th }}$ Ed.); P: 1043-1047. Lippincott- Raven: Philadelphia, USA.

20. Lee Y.; Costumbrado, J.; Hsu, Y.; and Kim YH.; 2012. Agarose gel electrophoresis for the separation of DNA fragments. The Journal of Visualized Experiments 62: pii: 3923. doi: 10.3791/3923.

21. Maiangwa, J.; Abdullahi, M.; and Ibrahim, M.; 2016. Antibacterial susceptibility spectrum of someGram negative bacteria from suspected Otitis media patients. African Journal of Microbiology Research 10: P: 12801285 .

22. Mohammad, K.; Prakriti, V.; and Ruby, N.; 2016. Bacterial aetiology and their Antibiotic susceptibility pattern of otitis media in pediatric age group. International Journal of Current Microbiology and Applied Sciences 5: P: 387-393.

23. Nishino, K.; and Yamaguchi, A.; 2004. Role of histone - like protein H-NS in multidrug resistance of Escherichia coli. Journal of Bacteriology 186: P: 1423-1429.

24. Nwankwo, I.; and Okeke, O.; 2014. Antibiogram of bacterial pathogens associated with otitis media at Federal Medical Centre Umuahia.; Nigeria. Sky Journal of Microbiology Research 2: P: 32 - 36.

25. Nyembue, D.; Tshiswaka, J.; and Sabue, M.; 2003. Bacteriology of Chronic otitis media among Congolese children 57: P: Acta Oto-Rhino-Laryngologica Belgica Journal: P: 205-217.

26. Ogbogu, P.; Eghafona, N.; and Ogbogu, M.; 2013. Microbiology of otitis media among children attending tertiary hospital in Benin city, Nigeria, Journal of Public Health and Epidemiology 5: P: 280-284.

27. Okesola, A.; and Fasinam O.; 2012. Trends in the resistance pattern of bacterial pathogens of otitis media in Ibadan, Nigeria. African Journal of Clinical and Experimental Microbiology 13: P: 46-48.

28. Ologe, F.; and Nwawolo, C.; 2002. Prevalence of chronic suppurative otitis media among school children in a rural community in Nigeria. Nigerian Postgraduate Medical Journal 9: P: 63-66. 
29. Oni, A.; Bakare R.; and Nwaorgu, O.; 2001. Bacterial agents of discharging ears and antimicrobial sensitivity pattern in children in Ibadan, Nigeria. West African Journal of Medicine 20: P: 131-135.

30. Pournaras, S.; Maniati, M.; and Spanakis, N.; 2005. Spread of efflux pump over-expressing Pseudomonas aeruginosa in a region with blaVIM endemicity. Journal of Antimicrobial and Chemotherapy 56: P: 761-764.

31. Rajat, P.; Deepak J.; Vikran, N.; 2013. Microbiology of Chronic Otitis media in a Tertially Care Setup of Utterrakhand State. North American Journal of Medical Sciences 5: P: 282-285.

32. Raper, B.; and Fennell, D.; (1965). The genus Aspergillus. Williams and Wilkins: Baltimore, USA. P: 246.

33. Rejitha, M.; Sucilathangam, G.; and Kanagapriya, M.; 2015. Isolation of Candida and its speciation in various samples in a tertiary care hospital in North Karnataka, India. International Journal of Current Microbiology and Applied Sciences 4: P: 996-1000.

34. Richard, S.; Steele-moore, L.; and Goodwin A.; 2007. Antimicrobial susceptibility testing protocols. ( $1^{\text {stEd.), }}$ Boca Raton London New York; by Taylor \& Francis Group, London, UK. P: 193-236.

35. Riddel, W.; 1950. Riddel's simple method of slide culturing. Mycologia Journal 42: P: 265.

36. Rippon, W.; (1982). Candidiasis and the pathogenic yeasts. In medical mycology. (2 ${ }^{\text {nd }}$ Ed.), P: 484-453. Saunders: Philadelphia, USA.

37. Rovers, M.; Schilder, G.; and Zielhuis, A.; 2004. Otitis media. Lancet Journal 363: P: 465-473.

38. Sierra, A.; Mercedes, Z.; Beatriz, V.; 2011. Non-typeable H. influenzae and S. pneumoniae as primary causes of acute otitis media in Colombian children. Biomedical Center Journal of Infectious Diseases, 11: 4.

39. Singh, H.; Basu, R.; and Venkatesh, A.; 2012. Aerobic bacteriology of chronic suppurative otitis media in Rajahmundry, Andhra Pradesh, India. Biology and Medicine Journal 4: P: 73-79.

40. Susmita, K.; Moningi, N.; and Indrani, M.; 2014. Microbiological profile of chronic suppurative otitis media and in-vitro antibiotic sensitivity pattern in a tertiary care hospital. Otolaryngology on Line Journal 4: P: 22502259.

41. Van Hasselt, 2013. Bacteriology of chronic otitis media amongst children in Nkhotakota District of Malawi. ENT and Audiology News Journal 12.

42. Yusuf, E.; De Bel, A.; and Bouasse, J.; 2014. D-Zone test for detection of inducible clindamycin resistance using SirScan paper disks and Rosco Neo-Sensitabs at 25 and $15 \mathrm{~mm}$ distances. Journal of Medical Microbiology 63: P: 1052-1054. 